Effects of Positive and Negative Awe on Spirituality

Abrey Feliccia

Ithaca College

Honors thesis presented to the Ithaca College Psychology Department on May 4, 2018 Supervisor: Professor Leigh Ann Vaughn 


\begin{abstract}
Past research has found that awe is closely related to spiritual experiences. However, it is not clear whether positive awe and negative, threat-based awe have similar effects on self-judgments of spirituality. Negative awe includes feelings of fear that may impede peoples' experience of connecting with the transcendent. This experiment examined how recalled experiences of positive awe, negative awe, and amusement (a control condition for awe) affect feelings of spirituality. We found that people higher in religiosity reported more spirituality, which did not differ across experimental conditions. Additionally, we found that participants lower in religiosity reported more spirituality in the positive and negative awe conditions than in the amusement condition. Results on other dependent variables in the study suggest that participants low in religiosity used their experiences of awe as information for judgments about their spirituality, whereas participants higher in religiosity may have directly accessed views of themselves as spiritual.
\end{abstract}




\section{Effects of Positive and Negative Awe on Spirituality}

My two brothers and I had just come to this country.- -We were dead tired and just about ready to fall into bed, when one of my brothers called from the bathroom, "Look at that. Wow!' He had filled the bathtub with hot water and was now adding cold. As hot and cold water mingled, the different densities of the currents caused a strange dance of shadows on the bottom of the tub. But there we stood, the three of us, for a long time totally absorbed in silent contemplation.-- Reality had caught us unaware and had touched our hearts.

(Steindl-Rast, 1983, p. 36)

...by the glimmer of the half-extinguished light, I saw the dull yellow eye of the creature open; it breathed hard, and a convulsive motion agitated its limbs. How can I describe my emotions at this catastrophe, or how delineate the wretch whom with such infinite pains and care I had endeavoured to form?-- I had desired it with an ardour that far exceeded moderation; but now that I had finished, the beauty of the dream vanished, and breathless horror and disgust filled my heart.

(Shelley, 1818, p. 43)

The two quotations above are about very different experiences of awe, one positive and the other negative. Awe occurs in the presence of something vast that makes us go beyond our existing schemas or frames of reference to make sense of it (Bai et al., 2017). Moments of awe can be described as times of elevation, peak experience, and admiration (Bai et al., 2017), but some are also times of fear (Gordon et al., 2017). The first quotation above is about an experience of awe that has almost a spiritual quality, while the second quotation above is about 
an experience of awe that is also horrific. In general, do experiences of positive awe enhance feelings of spirituality compared to experiences of negative, threat-based awe? This research is the first to test this hypothesis.

Experiences of spirituality can involve feeling deeply connected to everything, a sense of timelessness, and a feeling of merging with a power or force greater than the self (MacDonald et al., 2015). More generally, spirituality is a concern with the transcendent, mystical, and sacred, combined with the notion that there is more to life than humans can fully grasp (MacDonald et al., 2015). Research has revealed positive correlates of spirituality ranging from psychological well-being to pro-social behavior (Hill \& Pargament, 2008; Koenig, Pearce, Nelson, \& Erkanli, 2016; Piff, Feinberg, Stancato \& Keltner, 2015). For example, spirituality can serve as a mental framework that contributes to motivation, emotional strength, coping, and meaning in life (Hill \& Pargament, 2008). Additionally, research has shown that daily spiritual experiences relate to faster resolution of symptoms of depression (Koenig et al., 2016). Experiences of awe may enhance experiences of spirituality (e.g., Preston \& Shin, 2017). If so, it is important to understand potential boundary conditions of such an effect, such as differences between positive and negative awe.

One thing on which positive and negative awe do not appear to differ is the experience of small self (Piff et al., 2015). With that said, there is an aspect of the small-self experience that could help link awe to experiences of spirituality. Piff et al. (2015) distinguished between two aspects of the experience of small self. One is the experience of vastness vis-à-vis the self - that is, the feeling of being small in relation to one's surroundings and the recognition of something greater than one's self. The other is the experience of diminished self - that is, of one's personal concerns being less important. Vastness vis-à-vis the self is conceptually similar to the 
experiential aspect of spirituality because both of these constructs include aspects of connection to vastness. For example, questionnaire items measuring vastness vis-à-vis the self include, "I feel the presence of something greater than myself" and "I feel part of some greater entity" (Piff et al., 2015, p. 891). Items measuring the experiential aspect of spirituality include, "I have had an experience in which I seemed to be deeply connected to everything" and "I have had an experience in which I seemed to go beyond my normal everyday sense of self" (MacDonald et al., 2015, p. 13). In contrast, diminished self seems less conceptually similar to spirituality. Diminished-self questionnaire items include, "I feel small relative to something more powerful than myself" and "I feel like my own day-to-day concerns are relatively trivial" (Piff et al., 2015, p. 891). If vastness vis-à-vis the self is high in both positive awe and negative awe and vastness vis-à-vis the self could help connect awe to the experience of spirituality, positive and negative awe might have similar effects on the experiential aspect of spirituality. However, we believe that positive and negative awe will have different effects on spirituality because of the motivations associated with positive and negative emotions.

Positive emotions tend to help people broaden and build their physical, cognitive, and social resources (Fredrickson, 2001). For example, amusement can help people cope with ideas that are painful by exaggerating the threatening idea while altering the feeling (Vaillant, 2000). In contrast, awe motivates people to stop and take in new information in order to accommodate their schemas to something that is vast (Shiota et al., 2017). Feelings of vastness vis-à-vis the self and self-diminishment distinguish both positive and negative awe from amusement (Piff et al., 2015). However, positive and negative awe could differ from each other in how much people want to approach the awe-provoking stimulus. In positive awe, people may not only experience cognitive broadening, but also a desire to become absorbed in what inspires the awe, such as in 
the first quotation by Steindl-Rast (1999). In contrast, we believe that negative, threat-based awe will not enhance experienced spirituality because of the action tendencies associated with fear.

Research suggests that fear narrows attention to focus on basic needs of survival (for a review, see Fredrickson, 2000). Compared to positive awe, negative, threat-based awe increases feelings of fear and anxiety, elevates fear-related arousal, and reduces feeling of control (Gordon et al., 2017). Negative awe also can increase feelings of powerlessness and decrease subjective well-being (Gordon et al., 2017). Gordon et al.'s (2017) research suggests that negative awe can lead people to be vigilant and to focus on protecting themselves against something threatening. These tendencies are unlike what happens in positive awe, which leads people to broaden their schemas and become pleasantly absorbed in contemplating the environment.

Thus, although positive and negative awe both involve feeling small, the subjective experience of that smallness in positive awe could involve tendencies to take in something vast, whereas in negative awe it could involve tendencies to escape or protect the self from something vast. Negative awe could relate to feeling both self-diminishment and a sense of vastness vis-àvis the self. However, fear and anxiety could prevent the intrinsic motivation to create a bond with transcendent vastness that characterizes spiritual experiences (Piedmont et al., 2009). Thus, we expect that experiential spirituality will be higher when people experience positive awe than when they experience negative awe or amusement.

Research shows that religiosity and spirituality are positively correlated (MacDonald et al., 2015; Piedmont, Ciarrochi, Dy-Liacco, \& Williams, 2009). Thus, it is important to see how much our expected effects differ among people who differ in their level of religious identification. Items measuring religious identification include "I see myself as a religiously oriented person" and "I believe that going to religious services is important" (MacDonald et al., 
2015, p. 13). We expect that people who are higher in religious identification will report stronger experiences of spirituality. However, we do not expect religiosity to interact with emotion to affect self-reported spirituality.

To test these hypotheses, this study asked participants to bring to mind and report an experience of positive awe, negative awe, or amusement, and then report their current emotions and feelings of self-diminishment and vastness vis-à-vis the self. Then they completed a measure of spirituality. I predicted that experiential spirituality would be highest in the positive awe condition. Additionally, I explored how diminished self, vastness vis-à-vis the self, and emotions of awe, amusement, fear, general positive emotions, and general negative emotions help explain these effects. Finally, I tested the hypotheses that people scoring higher on religious identification will report more spirituality, but that religious identification would not interact with the kind of emotion participants brought to mind to affect feelings of spirituality or the other dependent variables in the study.

\section{Method}

\section{Participants}

Participants were a convenience sample of 133 Ithaca College students 18-22 years old, enrolled in psychology courses that provided additional options for extra credit. There were 109 females, 21 males, and 3 participants who identified as "other." English was the first language of 124 participants, English and some Spanish/or French were first languages of two participants, and four participants had either German, Hindi, Russian, or Spanish as their first language. For nation of origin, 124 participants reported the U.S., four reported China, one reported Germany, one reported India, one reported Jamaica, one reported Nicaragua, and one reported Russia. Participants could mark all the racial/ethnic groups to which they belong; 116 participants 
reported White, eight reported Asian, eight reported Black or African-American, nine reported Hispanic or Latino, three reported multiethnic, one reported Native American, and one reported other. I eliminated four from the analyses; one of these participants reported the same answer on each of the questions and three did not follow the writing instructions.

Participants participated in the survey through the Ithaca College Sona System. I recruited for participants in classes by reading a recruiting script that described the study as involving emotions and personal experiences.

\section{Design and Materials}

After participants consented to participate in the research, they completed the online questionnaire, which took between 20 and 30 minutes. The online survey randomly assigned participants to one of three conditions: negative awe, positive awe, or amusement. In each condition, participants received a description of their assigned emotion, and they recalled and wrote about a personal experience with that emotion. The instructions for the awe conditions were from research conducted by Gordon et al. (2017), and the instructions for the amusement condition were ones that we created to be structurally similar. Participants in the negative, threat-based awe condition read the following instructions (Gordon et al., 2017, p. 316):

Awe is a strong feeling of reverence and wonder. Often we feel awe in response to natural disasters such as earthquakes, hurricanes, or volcanic eruptions. We can also feel awe in response to people who cause large-scale devastation, such as Hitler and the vast horrors of the Second World War. Other times, we might feel awe towards an idea that is amazing and scary at the same time- - such as the mysteries of space. Please take a moment to recall a time when you felt intense awe like the examples described above or depicted in the photo below. 
Participants in the positive awe condition read the following instructions (Gordon et al., 2017, p. 316):

Awe is a strong feeling of reverence and wonder. Often we feel awe in response to vast, beautiful landscapes and natural wonders such as tall mountains, expansive vistas, or large waterfalls. We can also feel awe in response to people who cause large-scale change such as Nelson Mandela and his role in ending apartheid in South Africa. Other times we might feel awe towards an idea that is amazing and wondrous - such as the mysteries of space. Please take a moment to recall a time when you felt intense awe like the examples described above or depicted in the photo below.

Participants in the amusement condition read the following instructions:

Amusement is a strong feeling of finding something funny. Often we feel amused when we encounter something unexpected that makes us laugh. We can also feel amused in response to people who violate our expectations in a nonthreatening way, such as a good friend who does something that is just funny in the moment. Other times we might feel amused toward an idea that is unexpected, such as something that an animal might or might not say if it could talk. Please take a moment to recall a time when you felt intense amusement like the examples described above or depicted in the photo below.

Pictures reinforced the instructions (see Figures 1-3). After the page with their assigned writing task, participants received several pages of self-report scales, which I describe next. The Cronbach's alphas for these scales are in Table 1.

Current feelings. On the page after they recalled and described an autobiographical memory, participants indicated how much they agreed with five statements related to vastness vis-à-vis the self (Piff et al, 2015), including "I feel the presence of something greater than 
myself" and "I feel part of some greater entity." Additionally, they reported their feelings of diminished self with five items by Piff et al. (2015, p. 892), including "I feel small or insignificant," "I feel insignificant in the grand scheme of things," and "I feel small in relation to something more powerful than myself." (For the full vastness vis-à-vis the self and diminished self scales, see Appendix A.) They also answered two items about their desire to approach or merge with something vast and two items about their desire to avoid or protect themselves from something vast. Additionally, participants reported their feelings of awe (awe, wonder, and amazement), fear (fear, nervousness, and anxiety), amusement (amused, tickled and entertained), general positive affect (contentment, joy, and gratitude), and general negative affect (anger, disgust, and sadness). They responded to all of these items on a scale from 1 (not at all) to 7 (very much). Participants received the items on this page in randomized order.

Experiential spirituality. On the next page, participants received the six-item Experiential/Phenomenological Dimension (EPD) subscale from MacDonald and colleagues' Expressions of Spirituality Inventory (MacDonald et al., 2015). Items on this scale include "I have had an experience in which I seemed to be deeply connected to everything" and "I have had an experience in which I seemed to go beyond my normal everyday sense of self." Participants responded on a seven-point response scale, from 1 (strongly disagree) to 7 (strongly agree). (For the full scale, see Appendix A.)

Demographics. On the next page, participants answered questions regarding age, gender, ethnicity, nationality, language spoken in home, and education level.

Religious identification. On the page after the demographic questions, participants received a measure of religious identification: the six-item Religiousness (REL) subscale from MacDonald and colleagues' Expressions of Spirituality Inventory (MacDonald et al., 2015). 
Items on this scale include "I believe that going to religious services is important" and "I see myself as a religiously oriented person." Participants responded on a five-point scale ranging from 1 (strongly disagree) to 7 (strongly agree). (For the full scale, see Appendix A.)

Impressions of the study and debriefing. Next, the questionnaire asked participants about their impressions of the study. Finally, participants received a debriefing page about the purpose of the study that included Professor Vaughn's contact information in case participants wanted additional information about the study.

\section{Results}

\section{Overview of Analyses}

For the main analyses, one-way ANOVAs tested for differences between the negative awe, positive awe, and amusement conditions on all eleven dependent measures. I used Tukey HSD post-hoc tests to examine which groups were significantly different for any ANOVA that showed a significant effect. Planned comparisons compared the awe conditions to the amusement condition and the positive emotion conditions to the negative awe condition. Finally, I ran multiple regressions with interaction effects to examine interactions between religious identification and the independent variable on each dependent variable.

Before conducting the other analyses, I examined whether there were condition effects on religiosity. A one-way ANOVA revealed no significant differences in religiosity between levels of the independent variable, $F(2,130)=.691, p=.503$.

I centered religiosity for use in multiple regression analyses with interaction effects. The experimental condition variable was dummy-coded with each condition as a reference group for the multiple regression analyses. For the remaining analyses, I only report the significant effects.

\section{Emotions}


Awe. A one-way between groups analysis of variance revealed a significant effect of experimental conditions on the feeling of awe: $F(2,130)=3.19, p=.045$. Table 1 shows the means for the conditions of the independent variable on this and the other dependent variables. The planned comparison of amusement versus awe conditions (coded as amusement $=-2$, negative awe $=1$, positive awe $=1$ ) was significant: $F(2,132)=3.19, p=.045$. Simultaneously regressing participants' feelings of awe onto experimental conditions, with amusement as the dummy-coded reference, centered religiosity, and the interaction with each dummy code, revealed only a significant difference in feelings of awe between the amusement and positive awe conditions $(b=.772, t=2.34, p=.021)$.

Amusement. The analyses revealed no significant effects on amusement.

Tension. The analyses revealed no significant effects on tension.

General positive emotion. The index of general positive emotion consisted of measures of contentment, joy, and gratitude. A one-way between groups analysis of variance revealed no significant overall effect of the experimental conditions on this index: $F(2,130)=2.70, p=.071$. However, one planned comparison $($ coded as amusement $=1$, negative awe $=-2$, positive awe $=$ 1) revealed that general positive emotion was significantly higher in the positive affect conditions than in the negative awe condition, $t(130)=2.32, p=.022$. Simultaneously regressing participants' feelings of general positive emotions onto experimental conditions, with positive awe as the dummy-coded reference revealed a significant difference in positive emotion between the positive awe and negative awe conditions $(b=-.603, t=-2.13, p=.035)$.

General negative emotion. This index consisted of measures of anger, sadness, and disgust. The analyses revealed no significant effects on this index.

\section{Aspects of Small Self}


Vastness vis-à-vis the self. A one-way between groups analysis of variance revealed no significant difference in feeling of vastness vis-à-vis the self between the experimental conditions: $F(2,130)=2.86, p=.061$. However, a planned comparison $($ coded as amusement $=-$ 2, negative awe $=1$, positive awe $=1$ ) revealed that vastness vis-à-vis the self was significantly higher in the awe conditions than in the amusement condition: $F(1,130)=2.24, p=.027$. Simultaneously regressing participants' feelings of vastness vis-à-vis the self onto experimental conditions, with amusement as the dummy-coded reference, centered religiosity, and the interaction with each dummy code, revealed a significant main effect of religiosity $(b=.300, t=$ $3.64, p<.001)$.

Diminished self. Simultaneously regressing participants' feelings of self-diminishment onto experimental conditions, with negative awe as the dummy-coded reference, centered religiosity, and the interaction with each dummy code, revealed a significant main effect of religiosity $(b=-.205, t=-2.29, p=.024)$.

\section{Approach and Avoidance}

Desire to approach something vast. A one-way between groups analysis of variance revealed a significant effect of condition on participants' desire to approach something vast: $F(2$, $130)=3.94, p=.022$. Post-hoc comparisons using the Tukey HSD test indicated that the mean scores in the amusement and negative awe conditions were significantly different from one another. A planned comparison (coded as amusement $=1$, negative awe $=-2$, positive awe $=1$ ) revealed that desire to approach something vast was significantly higher in the negative awe condition than in the positive affect conditions, $t(130)=-2.813, p=.006$. Simultaneously regressing participants' feelings of wanting to approach something vast onto experimental conditions, with amusement as the dummy-coded reference, centered religiosity, and the 
interaction with each dummy code, revealed a significant difference in desire to approach between amusement and negative awe conditions $(b=.613, t=2.21, p=.029)$.

Desire to avoid something vast. A one-way between groups analysis of variance revealed a significant effect of conditions on participants' desire to avoid something vast: $F(2$, $130)=3.47, p=.034$. Post-hoc comparisons using the Tukey HSD test indicated that the mean scores in the amusement condition and the negative awe condition were significantly different from one another. Additionally, a planned comparison $($ coded as amusement $=1$, negative awe $=$ -2 , positive awe $=1$ ) revealed that desire to avoid something vast was significantly higher in the negative awe condition than in the positive affect conditions, $t(130)=-2.537, p=.012$. Simultaneously regressing participants' feelings of wanting to avoid something vast onto experimental conditions, with amusement as the dummy-coded reference, centered religiosity, and the interaction with each dummy code, revealed a significant difference in desire to avoid between amusement and negative awe conditions $(b=.760, t=2.56, p=.012)$.

\section{Experiential spirituality}

A one-way between groups analysis of variance revealed no significant difference in experiential spirituality between the experimental conditions: $F(2,130)=2.61, p=.077$. However, a planned comparison (coded as amusement $=-2$, negative awe $=1$, positive awe $=1$ ) revealed that experiential spirituality was significantly higher in the awe conditions than in the amusement condition, $t(130)=2.042, p=.043$. Simultaneously regressing participants' experienced spirituality onto experimental conditions, with the amusement condition as the dummy-coded reference, centered religiosity, and the interaction with each dummy code revealed a significant main effect of religiosity $(b=.563, t=5.03, p<.001)$. Additionally, there was a significant interaction between religiosity and the amusement-positive awe dummy code $(b$ 
$=-.461, t=-2.99, p=.003)$, as shown in Figure 4. The simple slope of religiosity in the negative awe condition was $.286(b=.286, t=2.68, p=.008)$, whereas the simple slope of religiosity in the positive awe condition was $.102(b=.102, t=.96, p=.340)$. The simple slope of religiosity in the amusement condition was the main effect of religiosity.

\section{Discussion}

The goal of the current research was to examine the effect of awe on spirituality by looking at whether there are distinct effects of positive and negative awe, in contrast to amusement. We suspected that because of awe's link to the experience of small self (Piff et al., 2015) and the small self's link to spirituality, awe might enhance the experience of spirituality. Thus, we looked at measures of small self, vastness vis-à-vis the self and self-diminishment, in addition to feelings and motivations tied to negative and positive affect, such as desire to approach or avoid something vast, as possible explanations for the anticipated effects of different types of awe on spirituality. Additionally, we wanted to see how religiosity, which has been found to be positively correlated with spirituality (MacDonald et al., 2015; Piedmont, Ciarrochi, Dy-Liacco, \& Williams, 2009) interacted with experimental conditions to relate to different dependent measures.

Not surprisingly, there was a positive relationship between religiosity and experiential spirituality when averaging across the levels of the independent variable; overall, people who reported higher religiosity also reported higher experiential spirituality. However, there was no main effect for experimental condition on experiential spirituality. Instead, a planned comparison showed that experiential spirituality was higher in the awe conditions than in the amusement condition. Additionally, there was a Condition x Religiosity interaction: participants lower in religiosity reported greater experiential spirituality in the awe conditions than in the 
amusement condition, but participants higher in religiosity showed no effects of conditions on experiential spirituality. This interaction effect cannot be explained by effects on other variables such as small self, vastness vis-à-vis the self, positive affect, and so on, because there were no similar interaction effects on those measures. In other words, people high and low in religiosity did not respond differently to experimental conditions except with regard to experiential spirituality.

While it is not clear from our results why this pattern of effects occurred, we believe that people higher and lower in religiosity could have used different judgment strategies to answer questions about their experiential spirituality. The Affect Infusion Model (Forgas, 1995) distinguishes between four ways that affect can influence judgments. We believe that the two ways that are most relevant to the effects on experiential spirituality are direct access and substantive processing. Direct access occurs when people tap into a stored reaction to a situation or question that is similar to something they have encountered before. People high in religiosity may have used direct access when answering experiential spirituality items. That is, these participants may have had pre-existing judgments about their spirituality that they could easily access because of high familiarity. This access to a stored judgment may have reduced the impact of experimental conditions on their experiential spirituality judgments. In contrast, those low in religiosity may have been using substantive processing to judge their experiential spirituality. Substantive processing requires judgment of an atypical situation. It therefore uses more cognitive processing and can be more affected by mood. Since the question of spirituality could be more novel for less religious participants, they could have needed to arrive at a judgment on the spot. If these participants were motivated to arrive at a judgment that seemed accurate, they could have relied more on emotions that seemed more relevant to judgments of 
experiential spirituality: positive and negative awe, as opposed to amusement. We have no direct evidence that participants engaged in these processes, and future research could test these hypotheses.

The current results also suggest that our measures of desire to approach something vast and desire to avoid something vast may not be valid, because they did not relate to the experimental conditions as we had expected. Responses to both of these measures were significantly higher in the negative awe condition than in the positive awe condition or the amusement condition. We expect that these odd results may have occurred because these measures were confusing to participants. Future research should continue to address approach and avoidance tendencies associated with awe by developing more valid measures of these constructs than it appears we did. With these better measures it could be possible to answer questions such as: in an experience of awe with fear, will people be more likely to avoid the vastness they are experiencing or engage with it in some way?

\section{Constraints on Generality}

There are several constraints on the generality of these findings that could be interesting to address in future research. One set of constraints pertains to the participants. These results were from undergraduate students enrolled in psychology courses at Ithaca College. The demographics of the sample may impact the reproducibility of the results in other samples. For example, Ithaca College is not a religiosity-affiliated institution, and only $36.1 \%$ of our sample scored at the midpoint or above on religiosity. In more religious samples, most or all participants might directly access self-judgments of experiential spirituality. If so, the Condition $\mathrm{x}$ Religiosity interaction might not reproduce. 
Another set of constraints on generality pertains to the experimental setting. Participants used their own devices in the study, which could influence the effectiveness of the experimental manipulation. For example, there might be stronger effects of experimental conditions on the dependent variables if participants were placed in a lab setting where there was a large screen showing their assigned condition's picture. In addition, because this study did not take place in a lab, we could not control for the environment that participants were in, which could have affected the participant's immersion in the experimental condition in other ways and added error variance to the results.

Historical events could also impact the effectiveness of the experimental manipulation. Natural disasters can elicit negative awe, and rare astronomical events (e.g., a total solar eclipse) can elicit positive awe. No such events happened at our institution during the study. However, if a sample experienced such an event very close to the time they took the study, it could boost the power of the experiential manipulation. Our participants tended to write about experiences that were distant and sometimes even appeared to be positive in the negative awe condition. This likely reduced the effectiveness of the emotion manipulation compared to what could have occurred if participants had stronger experiences of negative awe to bring to mind.

\section{Conclusion}

It is important to understand the mechanisms that can case awe to affect spirituality. In this, study we wanted to examine how experiencing positive and negative awe can make people feel spiritual, possibly through experiences of vastness. In a way, experiential spirituality is the acceptance of vastness that makes us feel connected to something beyond ourselves. Can all types of awe or other vastness-related experiences act as a pathway to spirituality, or could spirituality and awe influence each other? There is still much more research to be done on the 
topic, but the present research reveals that awe can enhance spirituality and that positive and negative awe may not differ in their effects. 


\section{References}

Bai, Y., Maruskin, L. A., Chen, S., A.M., Stellar, J. E, McNeil, G. D., Peng, K., \& Keltner, D. (2017). Awe, the diminished self, and collective engagement: Universals and cultural variations in the small self. Journal of Personality and Social Psychology, 113, 185-209.

Cohen, A. B., Gruber, J., \& Keltner, D. (2010). Comparing spiritual transformations and experiences of profound beauty. Psychology of Religion and Spirituality, 2, 127-135.

Forgas, J. P. (1995). Mood and judgment: The Affect Infusion Model (AIM). Psychological Bulletin, 117, 39-66.

Fredrickson, B. L. (2001). The role of positive emotions in positive psychology. The broadenand-build theory of positive emotions. American Psychologist, 56, 218-226.

Gordon, A. M., Stellar, J. E., Anderson, C. L., McNeil, G. D., Loew, D., \& Keltner, D. (2017). The dark side of the sublime: Distinguishing a threat-based variant of awe. Journal of Personality and Social Psychology, 113, 310-328.

Hill, P. C.,, \& Pargament, K. I. (2008). Advances in the conceptualization and measurement of religion and spirituality: Implications for physical and mental health research. Psychology of Religion and Spirituality, S, 3-17.

Koenig, H. G., Pearce, M. J., Nelson, B., \& Erkanli, A. (2016) Effects on daily spiritual experiences of religious versus conventional cognitive behavioral therapy for depression. Journal of Religion and Health, 55, 1763-1777.

MacDonald, D. A. (2000). Spirituality: Description, measurement, and relation to the five factor model of personality. Journal of Personality, 68, 153-197.

MacDonald, D. A., Friedman, H. L., Brewczynski, J., Holland, D., Slagame, K. K., Mohan, K. 
K., Gubrij, Z., \& Cheong, H. (2015). Spirituality as a scientific construct: Testing its universality across cultures. PLOS ONE, 3, 1-38.

Piedmont, R. L., Ciarrochi, J. W., Dy-Liacco, G., \& Williams, J. E. G. (2009). The empirical and conceptual value of the spiritual transcendence and religious involvement scales for personality research. Psychology of Religion and Spirituality, 1, 162-179.

Piff, P. K., Dietze, P., Feinberg, M., Stancato, D. M., \& Keltner, D. (2015). Awe, the small self, and prosocial behavior. Journal of Personality and Social Psychology, 108, 883-399.

Preston, J. L. \& Shin, F. (2017). Spiritual experiences evoke awe through the small self in both religious and non-religious individuals. Journal of Experimental Social Psychology, 70, 212-221.

Shelley, M. (1818). Frankenstein. London: Lackington, Hughes, Harding, Mavor, \& Jones.

Steindl-Rast, D. (1983). The Listening Heart: The Art of Contemplative Living. New York: The Crossroad Publishing Company.

Vaillant, G. E. (2000). Adaptive mental mechanisms: Their role in a positive psychology. American Psychologist, 55, 89-98. 
Table 1. Means and standard deviations of dependent variables at each level of the experimental condition

\begin{tabular}{|c|c|c|c|c|c|c|c|}
\hline & & \multicolumn{2}{|c|}{ Positive Awe } & \multicolumn{2}{|c|}{ Negative Awe } & \multicolumn{2}{|c|}{ Amusement } \\
\hline & ach's & & & & & & \\
\hline Measures & $\alpha$ & $M$ & $S D$ & $M$ & $S D$ & $M$ & $S D$ \\
\hline \multicolumn{8}{|l|}{ Experiential } \\
\hline Spirituality & 0.85 & 4.14 & 1.16 & 4.42 & 1.43 & 3.77 & 1.43 \\
\hline Religiosity & 0.94 & 3.4 & 1.76 & 3.51 & 1.72 & 3.1 & 1.64 \\
\hline Small Self & 0.83 & 4.47 & 0.86 & 4.41 & 0.79 & 4.11 & 0.68 \\
\hline \multicolumn{8}{|l|}{ Vastness vis-à-vis the } \\
\hline self & 0.83 & 4.75 & 1.11 & 4.56 & 1.02 & 4.23 & 0.97 \\
\hline Diminished Self & 0.7 & 4.19 & 0.94 & 4.27 & 1.2 & 3.98 & 0.92 \\
\hline Tension & 0.91 & 3.97 & 1.77 & 4.22 & 1.63 & 3.76 & 1.61 \\
\hline Awe & 0.91 & 4.76 & 1.67 & 4.63 & 1.5 & 3.99 & 1.43 \\
\hline Amusement & 0.89 & 4.05 & 1.67 & 3.44 & 1.63 & 3.81 & 1.3 \\
\hline Negative Emotion & 0.91 & 3.17 & 1.84 & 3.55 & 1.79 & 2.93 & 1.51 \\
\hline Positive Emotion & 0.8 & 4.8 & 1.27 & 4.22 & 1.48 & 4.78 & 1.22 \\
\hline Desire to Approach ${ }^{a}$ & 0.71 & 3.85 & 1.33 & 4.52 & 1.32 & 3.82 & 1.35 \\
\hline Desire to Avoid ${ }^{\mathrm{b}}$ & 0.78 & 3.03 & 1.4 & 3.58 & 1.45 & 2.83 & 1.3 \\
\hline
\end{tabular}

Note: ${ }^{\text {ab }}$ These two item scales have Pearson $r$. 


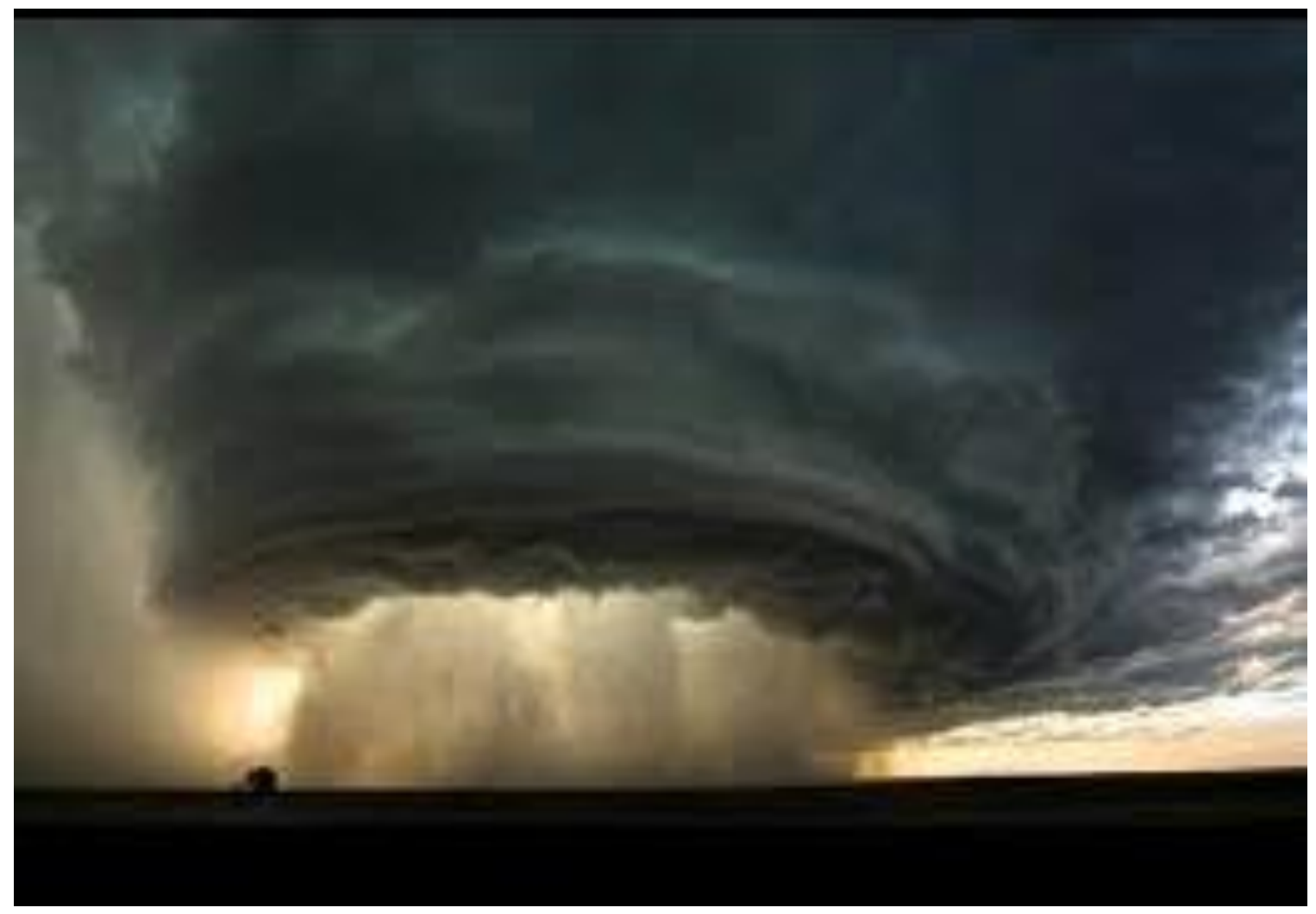

Figure 1. Negative awe 


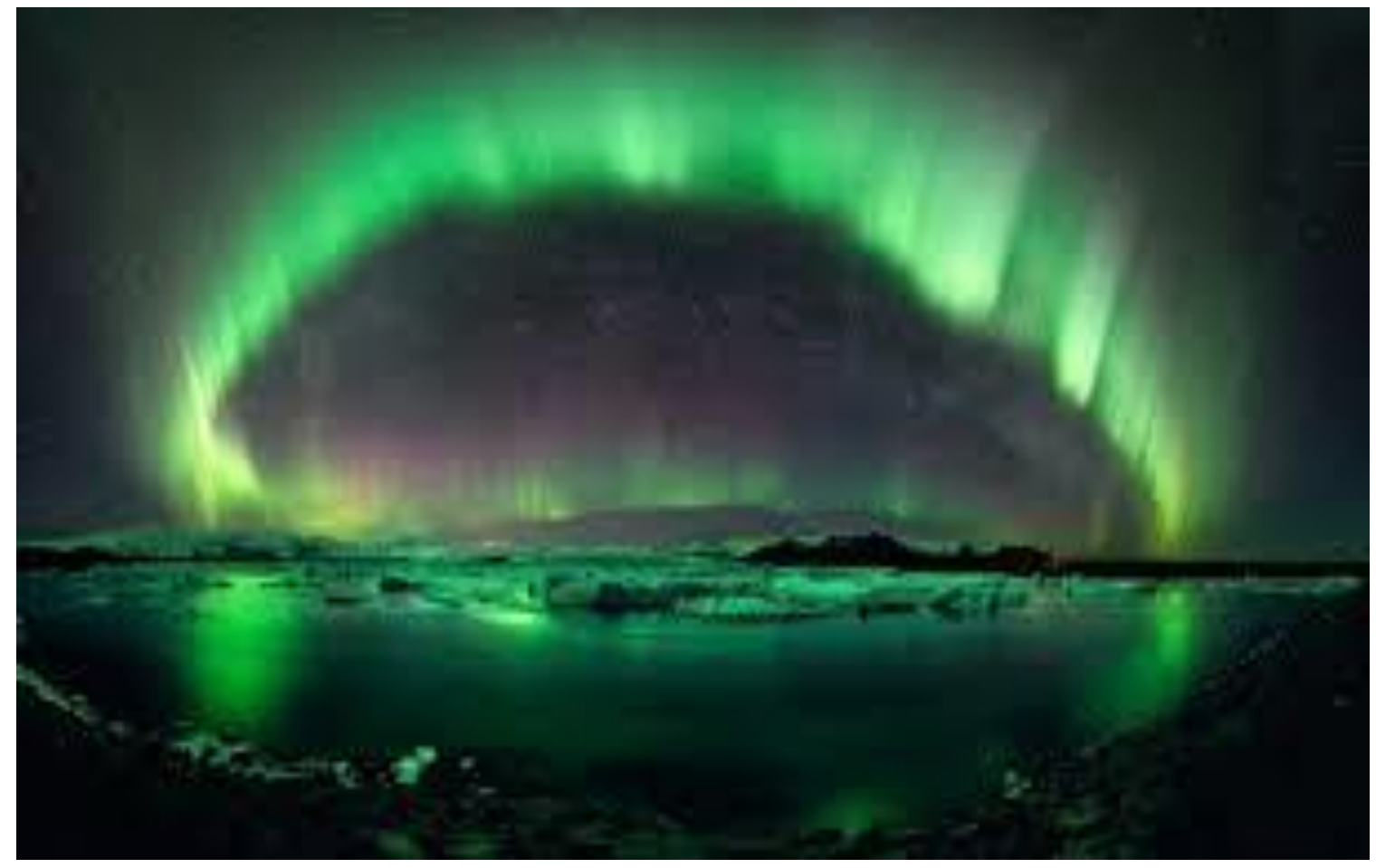

Figure 2. Positive awe 


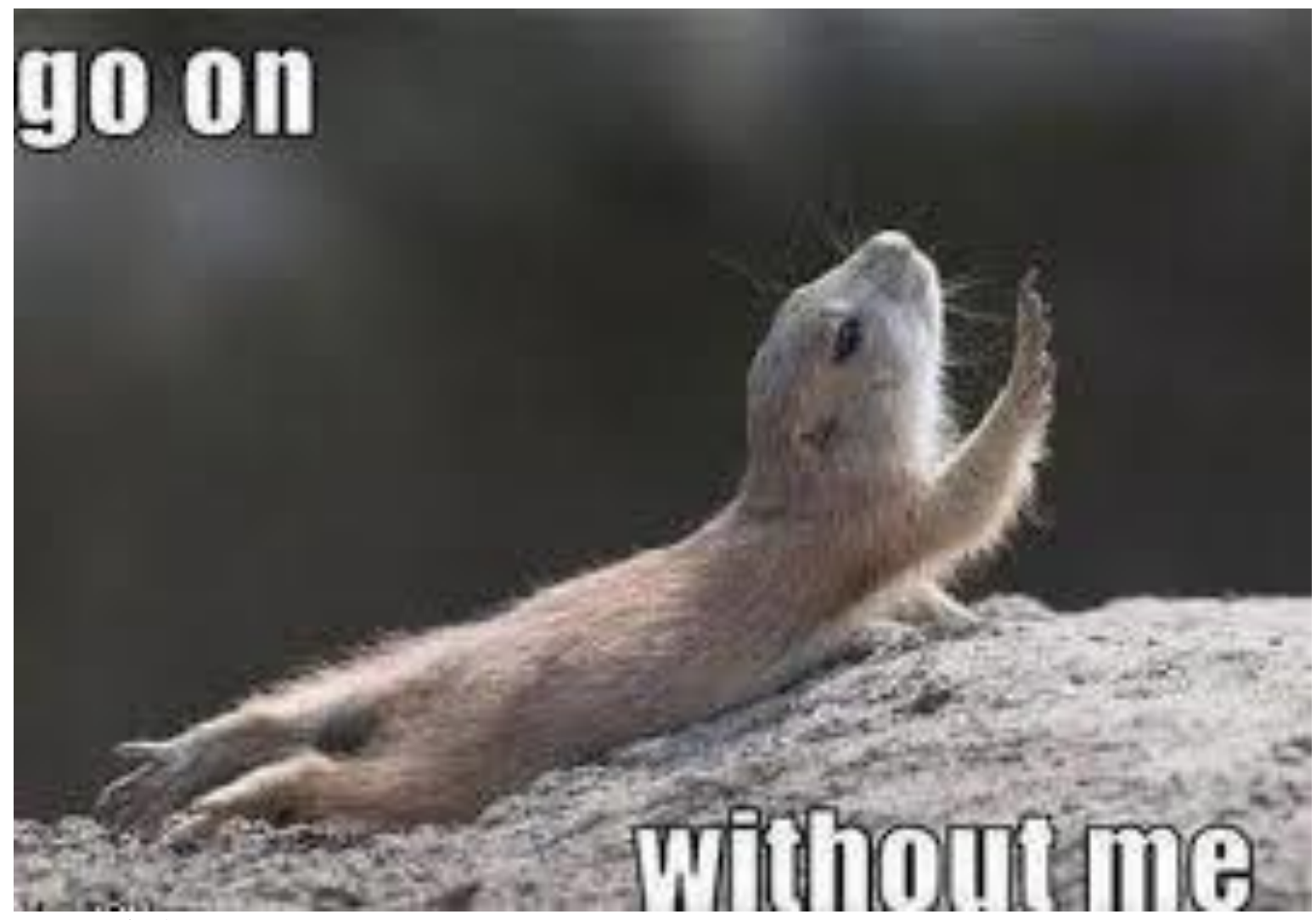

Figure 3. Amusement 


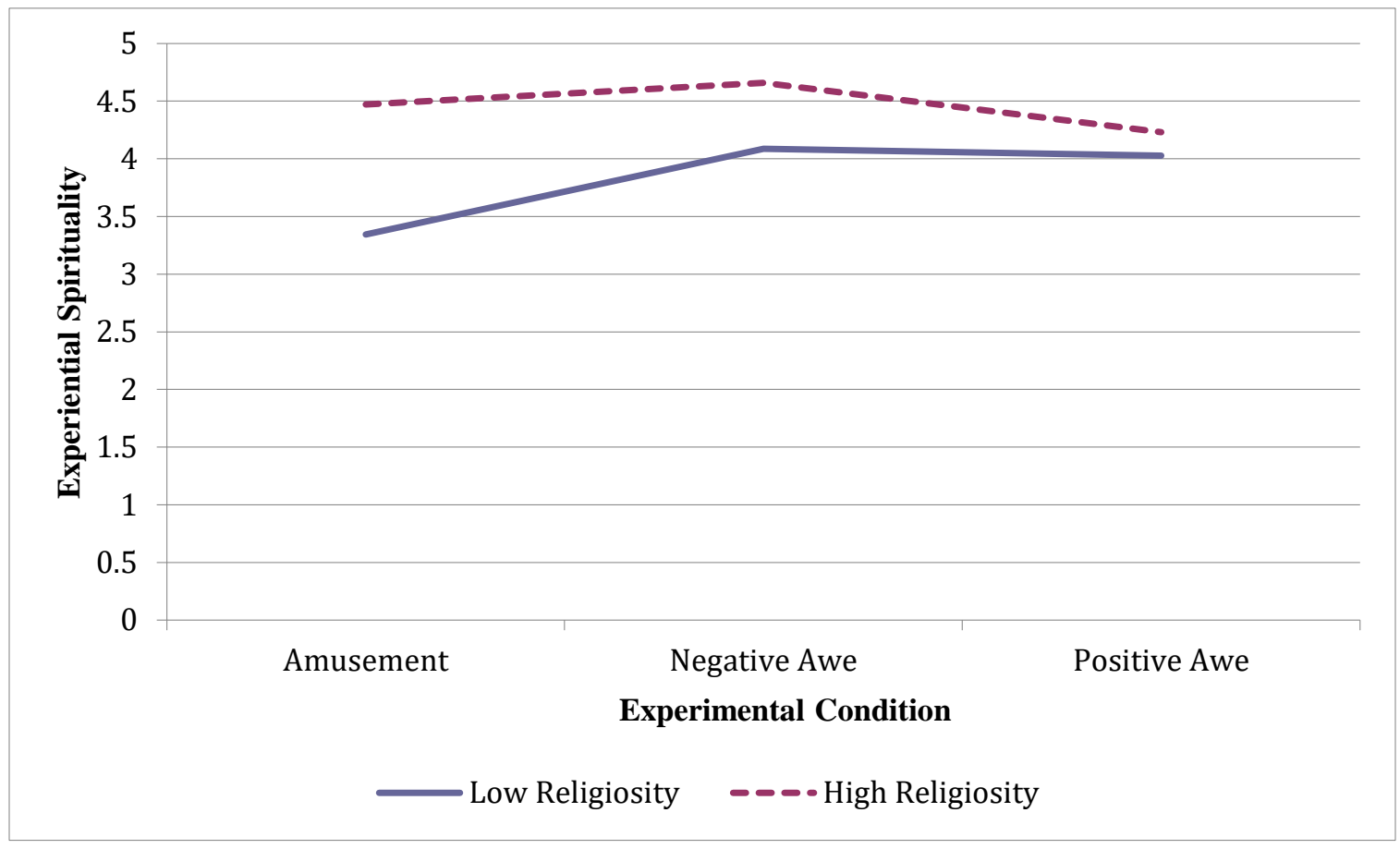

Figure 4. Interaction between religiosity and experiential spirituality at each level of the experimental condition. 


\section{Appendix A}

Vastness vis-à-vis the Self

1. I feel the presence of something greater than myself.

2. I feel part of some greater entity.

3. I feel like I was in the presence of something grand.

4. I feel like I was a part of a greater whole.

5. I feel the existence of things more powerful than myself.

Diminished Self

1. I feel small or insignificant

2. I feel like my own day-to-day concerns are relatively trivial

3. In the grand scheme of things, my own issues and concerns do not matter as much

4. I feel insignificant in the grand scheme of things

5. I feel small relative to something more powerful than myself

Experiential/Phenomenological Dimension (EPD) Items

1. I have had an experience in which I seemed to be deeply connected to everything.

2. I have had an experience in which I seemed to transcend space and time.

3. I have had a mystical experience.

4. I have had an experience in which I seemed to merge with a power or force greater than myself.

5. I have had an experience in which all things seemed divine.

6. I have had an experience in which I seemed to go beyond my normal everyday sense of self.

Religiousness (REL) items

1. I believe that going to religious services is important.

2. I feel a sense of closeness to a higher power.

3. I see myself as a religiously oriented person.

4. I see God or a Higher power present in all the things I do.

5. I practice some form of prayer.

6. I believe that God or a Higher Power is responsible for my existence. 